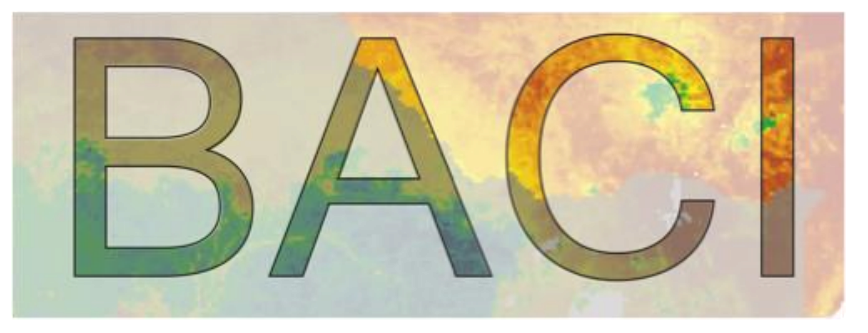

\title{
OCO-2 advances photosynthesis observation from space via solar-induced chlorophyll fluorescence
}

\section{Postprint version}

\author{
Y. Sun, C. Frankenberg, J. D. Wood, D. S. Schimel, M. Jung, L. Guanter, \\ D. T. Drewry, M. Verma, A. Porcar-Castell, T. J. Griffis, L. Gu, T. S. Magney, \\ P. Köhler, B. Evans, K. Yuen
}

\section{Published in:}

Science

Reference: Sun, Y., Frankenberg, C., Wood, J. D., Schimel, D. S., Jung, M., Guanter, L., et al. (2017). OCO-2 advances photosynthesis observation from space via solarinduced chlorophyll fluorescence. Science, 358(6360): eaam5747. doi:10.1126/science.aam5747

Web link: http://dx.doi.org/10.1126/science.aam5747 


\section{C0-2 advances photosynthesis observation from space via solar- induced chlorophyll fluorescence}

\author{
Y. Sun, ${ }^{*}$ C. Frankenberg, ${ }^{*}$ J. D. Wood, D. S. Schimel, M. Jung, L. Guanter, \\ D. T. Drewry, M. Verma, A. Porcar-Castell, T. J. Griffis, L. Gu, T. S. Magney, \\ P. Köhler, B. Evans, K. Yuen
}

INTRODUCTION: Reliable estimation of gross primary production (GPP) from landscape to global scales is pivotal to a wide range of ecological research areas, such as carbon-climate feedbacks, and agricultural applications, such as crop yield and drought monitoring. However, measuring GPP at these scales remains a major challenge. Solar-induced chlorophyll fluorescence (SIF) is a signal emitted directly from the core of photosynthetic machinery. SIF integrates complex plant physiological functions in vivo to reflect photosynthetic dynamics in real time. The advent of satellite SIF observation promises a new era in global photosynthesis research. The Orbiting Carbon Observatory-2 (OCO-2) SIF product is a serendipitous but critically complementary by-product of OCO-2's primary mission target-atmospheric column $\mathrm{CO}_{2}\left(\mathrm{X}_{\mathrm{CO}_{2}}\right)$. OCO-2 SIF removes some important roadblocks that prevent wide and in-depth applications of satellite SIF data sets and offers new opportunities for studying the SIF-GPP relationship and vegetation functional gradients at different spatiotemporal scales.

RATIONALE: Compared with earlier satellite missions with SIF capability, the OCO-2 SIF product has substantially improved spatial resolution, data acquisition, and retrieval precision. These improvements allow satellite SIF data to be validated, for the first time, directly against ground and airborne measurements and also used to investigate the SIF-GPP relationship and terrestrial ecosystem functional dynamics with considerably better spatiotemporal credibility.

RESULTS: Coordinated airborne measurements of SIF with the Chlorophyll Fluorescence Imaging Spectrometer (CFIS) were used to validate OCO-2 retrievals. The validation

The list of author affiliations is available in the full article online. *Corresponding author. Email: ys776@cornell.edu (Y.S.); cfranken@caltech.edu (C.F.)

Cite this article as Y. Sun et al., Science 358, eaam5747 (2017). DOI: 10.1126/science.aam5747 suburban Chicago, Illinois. shows close agreement between OCO-2 and CFIS SIF, with a regression slope of 1.02 and $R^{2}$ of 0.71. Landscape gradients in SIF emission, corresponding to differences in vegetation types, were clearly delineated by OCO-2, a capability that was lacking in previous satellite missions. The SIF-GPP relationships at eddy covariance flux sites in the vicinity of OCO-2 orbital tracks were found to be more consistent across biomes than previously suggested. Finally, empirical orthogonal function (EOF) analyses on OCO-2 SIF and available GPP products show highly consistent spatiotemporal correspondence in their leading EOF modes across the globe, suggesting that SIF and GPP are governed by similar dynamics and controlled by similar environmental and biological conditions.

CONCLUSION: OCO-2 represents a major advance in satellite SIF remote sensing. Our analyses suggest that SIF is a powerful proxy for GPP at multiple spatiotemporal scales and that high-quality satellite SIF is of central importance to studying terrestrial ecosystems and the carbon cycle. Although the possibility of a universal SIF-GPP relationship across different biome types cannot be dismissed, in-depth processbased studies are needed to unravel the true nature of covariations between

SIF and GPP. Of critical importance in such efforts are the potential coordinated dynamics between the light-use efficiencies of $\mathrm{CO}_{2}$ assimilation and fluorescence emission in response to changes in climate and vegetation characteristics. Eventual synergistic uses of SIF with atmospheric $\mathrm{CO}_{2}$ enabled by OCO-2 will lead to more reliable estimates of terrestrial carbon sources and sinks-when, where, why, and how carbon is exchanged between land and atmosphereas well as a deeper understanding of carbonclimate feedbacks.

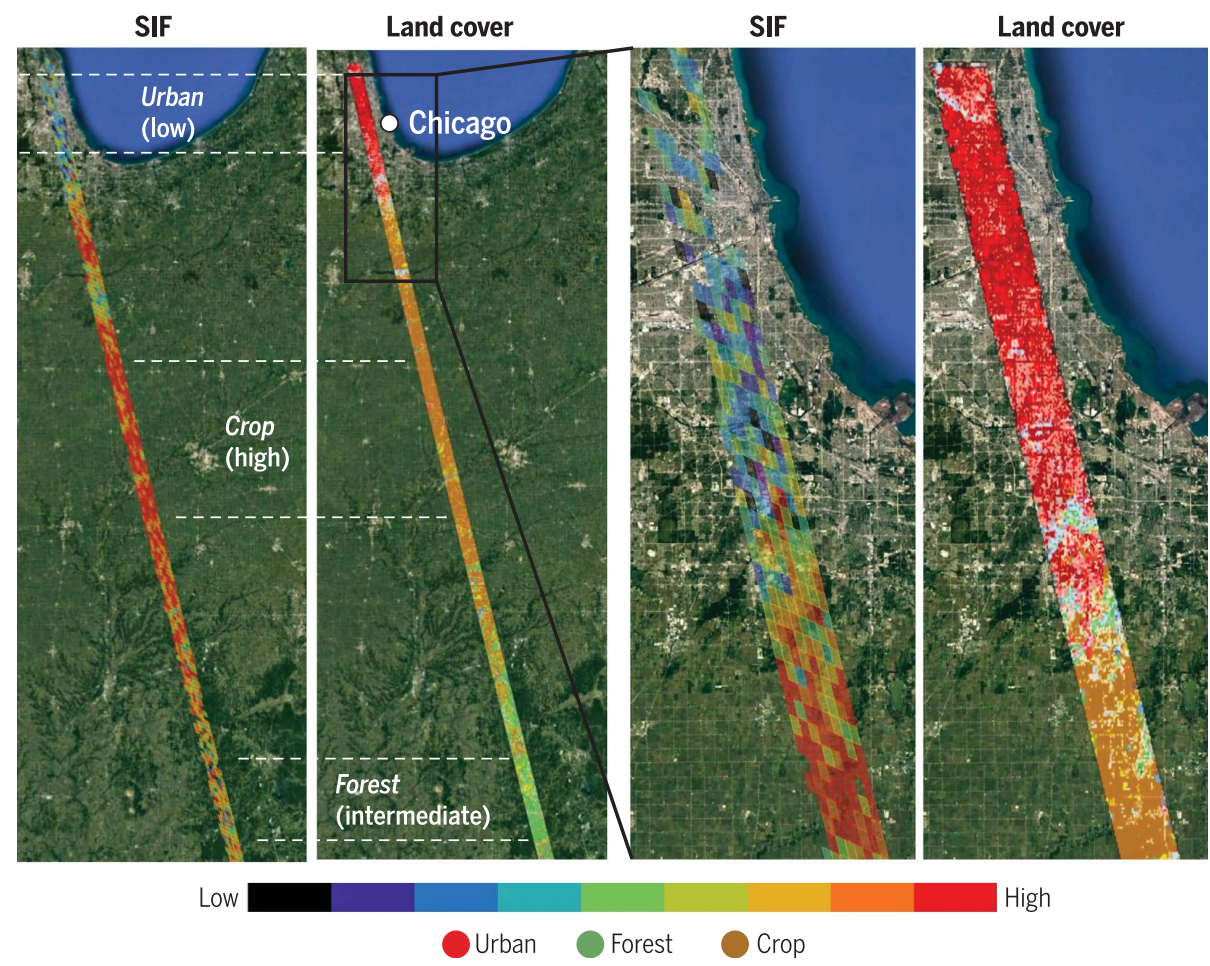

The marked ecological gradients depicted by OCO-2's high-resolution SIF measurements along a transect of temperate deciduous forests, crops, and urban area from Indiana to 


\section{C0-2 advances photosynthesis observation from space via solar- induced chlorophyll fluorescence}

\author{
Y. Sun, ${ }^{1 *} \dagger$ C. Frankenberg,,${ }^{2,1 *}$ J. D. Wood, ${ }^{3}$ D. S. Schimel, ${ }^{1}$ M. Jung, ${ }^{4}$ L. Guanter, ${ }^{5}$ \\ D. T. Drewry, ${ }^{1,6}$ M. Verma, ${ }^{7}$ A. Porcar-Castell, ${ }^{8}$ T. J. Griffis, ${ }^{9}$ L. Gu, ${ }^{10}$ T. S. Magney, ${ }^{1}$ \\ P. Köhler, ${ }^{2}$ B. Evans, ${ }^{11}$ K. Yuen ${ }^{1}$
}

Quantifying gross primary production (GPP) remains a major challenge in global carbon cycle research. Spaceborne monitoring of solar-induced chlorophyll fluorescence (SIF), an integrative photosynthetic signal of molecular origin, can assist in terrestrial GPP monitoring. However, the extent to which SIF tracks spatiotemporal variations in GPP remains unresolved. Orbiting Carbon Observatory-2 (OCO-2)'s SIF data acquisition and fine spatial resolution permit direct validation against ground and airborne observations. Empirical orthogonal function analysis shows consistent spatiotemporal correspondence between OCO-2 SIF and GPP globally. A linear SIF-GPP relationship is also obtained at eddy-flux sites covering diverse biomes, setting the stage for future investigations of the robustness of such a relationship across more biomes. Our findings support the central importance of high-quality satellite SIF for studying terrestrial carbon cycle dynamics.

P hotosynthesis, one of the most fundamental biological processes on Earth, provides food and oxygen to all higher life forms and regulates the capacity of terrestrial ecosystems to offset anthropogenic $\mathrm{CO}_{2}$ emissions. The continuing increase of atmospheric $\mathrm{CO}_{2}$ and its impact on climate are expected to affect photosynthesis in fundamental (1) but uncertain ways $(2,3)$. This uncertainty constitutes a critical constraint in the projection of future crop production (4) and carbon-climate feedbacks (5). However, we currently possess a limited capability to directly measure photosynthesis at spatial and temporal scales relevant for understanding and predicting future agricultural risks and roles of carbon-climate feedbacks in the Earth system. The approach of observing solar-

${ }^{1}$ Jet Propulsion Laboratory, California Institute of Technology, Pasadena, CA, USA. ${ }^{2}$ Division of Geological and Planetary Sciences, California Institute of Technology, Pasadena, CA USA. ${ }^{3}$ School of Natural Resources, University of Missouri, Columbia, MO, USA. "Max Planck Institute for Biogeochemistry, Jena, Germany. ${ }^{5}$ Helmholtz Centre Potsdam, German Research Centre for Geosciences, Potsdam, Germany. ${ }^{6}$ Joint Institute for Regional Earth System Science and Engineering, University of California, Los Angeles, CA, USA ${ }^{7}$ Consulting for Statistics, Computing, and Analytics Research, University of Michigan, Ann Arbor, MI, USA. ${ }^{8}$ Optics of Photosynthesis Laboratory, Department of Forest Sciences, University of Helsinki, Helsinki, Finland. ${ }^{9}$ Department of Soil, Water, and Climate, University of Minnesota, Saint Paul, MN, USA. ${ }^{10}$ Environmental Science Division, Oak Ridge National Laboratory, Oak Ridge, TN, USA. ${ }^{11}$ Faculty of Agriculture and Environment, School of Life and Environmental Science, The University of Sydney, Sydney, Australia.

*Corresponding author. Email: ys776@cornell.edu (Y.S.); cfranken@caltech.edu (C.F.) †Present address: School of Integrative Plant Science, Soil and Crop Sciences Section, Cornell University, Ithaca, NY, USA. induced chlorophyll fluorescence (SIF) globally from space is an important step toward alleviating this deficiency.

SIF, an emission from chlorophyll $a$ molecules excited by absorbed photons, is an optical signal emanating from the core of photosynthetic machinery and contains functional information about photosynthesis. The terrestrial SIF emission spectrum spans 660 to $850 \mathrm{~nm}$, with two peaks centered at 685 and 740. Although actively induced fluorescence has been used for decades to probe photosynthesis in vivo at molecular and leaf scales (6-10), passive SIF from a vantage point in space became available only recently (11-15). A major challenge of passive SIF remote sensing is to discern a small SIF emission from a much higher background signal-reflected sunlight. This challenge is overcome by measuring the in-filling of narrow solar Fraunhofer lines using high-resolution spectrometers. With this technique, the confounding effects of surface reflectance as well as atmospheric scattering and absorption are minimized, thereby facilitatpossessing the spectral and radiometric sensitivity to enable SIF retrievals include the Greenhouse Gases Observing Satellite (GOSAT), Global Ozone Monitoring Experiment-2 (GOME-2) onboard MetOp-A, and the SCanning Imaging Absorption spectroMeter for Atmospheric CHartographY these instruments were originally designed for measuring SIF, but they nevertheless provided initial data sets that revealed the feasibility of satellite SIF retrievals, albeit at very coarse spatial resolution. ing the SIF retrieval. The first spaceborne missions (SCIAMACHY) onboard Envisat (11-14). None of
The Orbiting Carbon Observatory-2 (OCO-2) SIF product is also a serendipitous but critical complementary by-product of OCO-2's primary mission target-atmospheric column $\mathrm{CO}_{2}$. The dynamics of column $\mathrm{CO}_{2}$ reflects net fluxes of production and consumption processes of both natural and anthropogenic origins. Thus, the serendipitous and primary products together form independent constraints on the $\mathrm{CO}_{2}$ source and sink distributions from the land and atmospheric perspectives, respectively. Their joint availability will help curb uncertainties in the estimate of regional and global carbon budgets and advance understanding terrestrial biosphere responses to climate change, which will eventually lead to better prediction of carbon-climate feedbacks.

In recent years, progress has been made in applying spaceborne SIF to study large-scale terrestrial ecosystem dynamics, covering a variety of topics such as high-latitude vegetation phenology, tropical carbon cycle seasonality, crop yield monitoring, and detection of impending droughts (16-23). However, it remains unclear to what extent the spatiotemporal variations of SIF and gross primary production (GPP) are related to each other, as well as how and at which scales SIF can be used to predict GPP. Here we will first discuss roadblocks in addressing these critical issues and then show how OCO-2 SIF helps to remove them and how it can be used to shed lights on SIF-GPP relationships at different spatiotemporal scales. In doing so, a variety of potential research opportunities enabled by this distinctive spaceborne SIF data product will also be introduced.

\section{High-resolution studies of vegetation functional gradients with $\mathrm{OCO}-2$ SIF products}

Studies of the relationship between vegetation and climate gradients are crucial to understanding biosphere dynamics. It has been difficult to use SIF retrievals from previous satellite missions to investigate heterogeneous landscapes because of their coarse spatial resolutions and limited sampling strategies (Fig. 1A). For example, the native footprint of GOME-2 is $40 \mathrm{~km}$ by $40 \mathrm{~km}$ (40 km by $80 \mathrm{~km}$ before 15 July 2013) (14), whereas GOSAT has a circular footprint of $10 \mathrm{~km}$ in diameter, with individual samples sparsely distributed across Earth's surface $(11,13)$. This severely masked out fine-scale variations that are key to studying vegetation functional gradients. In contrast, a nominal OCO-2 footprint is $1.3 \mathrm{~km}$ by $2.25 \mathrm{~km}$, with eight independent across-track measurements within its $10-\mathrm{km}$ swath width, yielding $\sim 10^{5}$ clear-sky SIF observations over land each day (24). This high data-acquisition density allows the use of averaging to effectively minimize random measurement uncertainty and to produce high-precision SIF products at an unprecedented high spatial resolution, even though the narrow swath reduces the extent of global coverage. For regions covered by orbital tracks of OCO-2, its SIF data sets can be used to quantify the heterogeneity of ecosystem structure and function and to detect fine-scale ecophysiological phenomena such as functional 

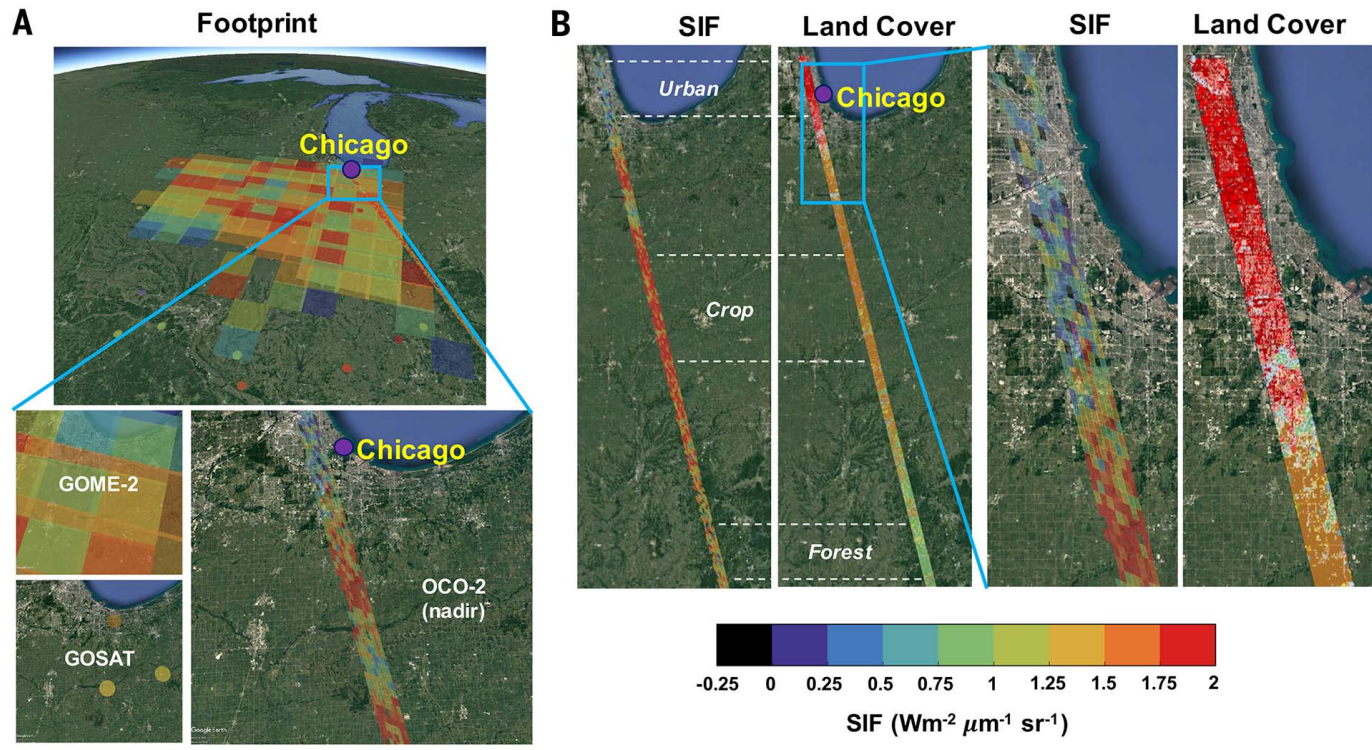

\begin{tabular}{|l}
\hline Open Water \\
\hline Perennial Ice/Snow \\
\hline Developed, Open Space \\
Developed, Low Intensity \\
Developed, Medium Intensity \\
Developed, High Intensity \\
\hline Barren Land (Rock/Sand/Clay) \\
\hline Deciduous Forest \\
Evergreen Forest \\
Mixed Forest \\
Dwarf Scrub* \\
\hline Shrub/Scrub \\
\hline Grassland/Herbaceous \\
\hline Pasture/Hay \\
Cultivated Crops \\
Woody Wetlands \\
Emergent Herbaceous Wetlands \\
NLC Land Cover Type \\
\end{tabular}

Fig. 1. High-resolution OCO-2 footprints and the marked ecological gradients depicted by OCO-2 SIF along a transect from Indiana to suburban Chicago, Illinois. (A) Spatial resolution of OCO-2 SIF (nadir mode, $1.3 \mathrm{~km}$ by $2.25 \mathrm{~km}$ ) compared with existing products from GOME-2 (40 km by $40 \mathrm{~km}$ ) onboard MetOp-A and GOSAT-Fourier Transform Spectrometer (10-km diameter). SIF is acquired during August overpass(es) in 2015: 20 August for OCO-2, 5 August for GOME-2, and entire month of August for GOSAT. (B) Visualization of the vegetation functional gradients across a transect of temperate deciduous forests, croplands, and urban area with OCO-2 SIF. The National Land Cover Database 2011 (NLDC 2011) (45), created by the Multi-Resolution Land Characteristics Consortium, is used here (spatial resolution: $30 \mathrm{~m}$ ). The rural-urban contrast is well characterized by the high-resolution OCO-2 SIF (the zoomed-in boxes). The asterisk indicates Alaska only. changes in ecologically and climatically sensitive regions. These regions include human-disturbed and heavily fragmented areas, as well as ecotones such as southern and northern boreal tree lines where forest expansion and contraction has been observed due to climate change.

OCO-2 SIF is capable of capturing the spatial gradients in SIF emission across diverse ecosystems. As an example, Fig. 1B shows a marked contrast of SIF in an August orbital track along a transect spanning forests, crops, and developed urban areas south of Chicago. Here we find that SIF of croplands far exceeds that of forests, whereas urban green areas emit a very weak signal. This example demonstrates that with its current level of retrieval precision, OCO-2 SIF has the capability to capture real-time photosynthetic activities. Although sharp contrasts in SIF between different vegetation types have been reported with ground-based measurements (25), none of the previous satellite missions were able to resolve such fine-scale functional transitions across ecosystems. As the data records provided by OCO-2 grow, it will be possible to use them in conjunction with column $\mathrm{CO}_{2}$ concentration measurements to investigate how vegetation functional gradients vary in response to changes in environmental conditions and how these gradients are related to spatial variations in the terrestrial carbon sink.

\section{Coordinated spaceborne and airborne SIF measurements for validation and optimizing retrieval algorithms}

So far, various retrieval algorithms have been developed and applied, depending on different spectrometer specifications. These algorithms can be classified into two broad categories. The first employs physically based approaches to fit narrow spectral windows and is used for spectrometers with very high spectral resolution (e.g., $<0.05 \mathrm{~nm}$; GOSAT and OCO-2). The second uses statistical approaches to fit relatively broad spectral windows and is for spectrometers with moderate spectral resolution (e.g., $~ 0.5 \mathrm{~nm}$; GOME-2). Because there is always a trade-off among spatial, temporal, and spectral resolutions, these two approaches have pros and cons in terms of retrieval robustness and sensitivity to atmospheric scattering and absorption, spatial resolution, and revisit time (26). Cross-mission comparisons with different spaceborne instruments have been performed, yet true validation of these retrieval algorithms with independent airborne or ground measurements of SIF has lagged behind the development of these previous spaceborne SIF products.

Toward that goal, the OCO-2 team developed the airborne Chlorophyll Fluorescence Imaging Spectrometer (CFIS). CFIS combines high spectral resolution $(<0.1 \mathrm{~nm})$ with a wide spectral coverage (737 to $772 \mathrm{~nm}$ ) (Fig. 2A), which is optimally suited for SIF retrievals and allows for testing both retrieval strategies mentioned above. Several validation campaigns with CFIS were carried out in 2015 and 2016 across a range of different ecosystems (including crops, grassland, and forests), under-flying the OCO-2 orbital tracks in Illinois, Iowa, Colorado, Nebraska, Minnesota, and California. Figure $2 \mathrm{~B}$ shows the initial validation flights in 2015, revealing a strong agreement between OCO-2 and CFIS SIF along latitudinal gradients.
The spaceborne and airborne measurements were linearly correlated, with a regression slope of 1.02 $\left(R^{2}=0.71\right.$, fig. S1), indicating that the latitudinal variation of SIF is well characterized by OCO-2 retrievals. Figure $2 \mathrm{C}$ shows fine-scale CFIS SIF retrievals over agricultural areas in southwest Minnesota, including a region affected by partial cloud cover. The Fraunhofer line-based SIF retrievals are insensitive to atmospheric scattering, which can be seen, as the partial cloud cover appears not to affect the SIF retrieval. As a comparison, a fourband [red-green-blue (RGB) + near-infrared (NIR)] context camera was used to derive RGB imagery and the normalized difference vegetation index (NDVI) at a much higher spatial resolution than CFIS. The reflectance-based NDVI is expectedly strongly affected by clouds in general, whereas SIF is only reduced in the optically thick parts of the cloud as well as over cloud shadows. In the SIF imagery, strong gradients between corn and soybean plots can be discerned, with soybean being more fluorescent in mid-August 2016, most likely related to an offset in planting dates between these two primary U.S. Midwest crops.

Such coordinated spaceborne and airborne measurements for the purpose of SIF validation have not been carried out for any previous satellite instruments with SIF capabilities. The CFIS validation data set will be an important step toward bridging the scale gaps between ground-based spectrometers-which are now being developed and deployed to examine fine temporal- and spatialscale functional SIF dynamics-and satellite-based measurements from OCO-2 and follow-on missions such as the European Space Agency Fluorescence 
Explorer (FLEX) (27). In fact, the airborne instrument HyPlant has been designed for preparing the launch of FLEX, and a number of campaigns have already been performed since $2012(28,29)$. In the coming years, these HyPlant campaigns will be continued, and potential synchronous flights with OCO-2 will greatly advance the development and optimization of SIF retrieval algorithms.

\section{Using OCO-2 SIF as a shortcut to estimating GPP}

A direct linkage between satellite observation and flux tower-based measurements is crucial for using remotely sensed SIF to estimate GPP at larger scales. This has not been possible in the past because previous missions had coarse spatial resolutions, low data-acquisition rates, and high observation uncertainties, which made it difficult to apply spaceborne and ground-based measurements in a synergistic and integrated fashion. For example, the spatial resolutions of
GOME-2 and SCIAMACHY (30 km by $60 \mathrm{~km}$ ) are much larger than a typical eddy covariance (EC) flux tower footprint, whereas GOSAT's sparse data acquisition severely restricted the possibility of reducing random retrieval errors via sample averaging. These limitations prevented simultaneous uses of spaceborne SIF and ground-based measurements for in-depth analyses of biomespecific responses. In contrast, OCO-2's fine spatial resolution (1.3 km by $2.25 \mathrm{~km}$ ), together with high data-acquisition, density alleviates such limitations. Thus, OCO-2 SIF data sets can be integrated with ground-based measurements to investigate the SIF-GPP relationship, at least for regions covered by OCO-2 orbital tracks.

We have identified multiple FLUXNET sites that are located in the direct or close vicinity of OCO-2 orbits $(30,31)$. These sites span structurally and functionally diverse ecosystems, including crops, temperate deciduous forests, and grasslands. We related OCO-2 SIF to GPP derived from
A
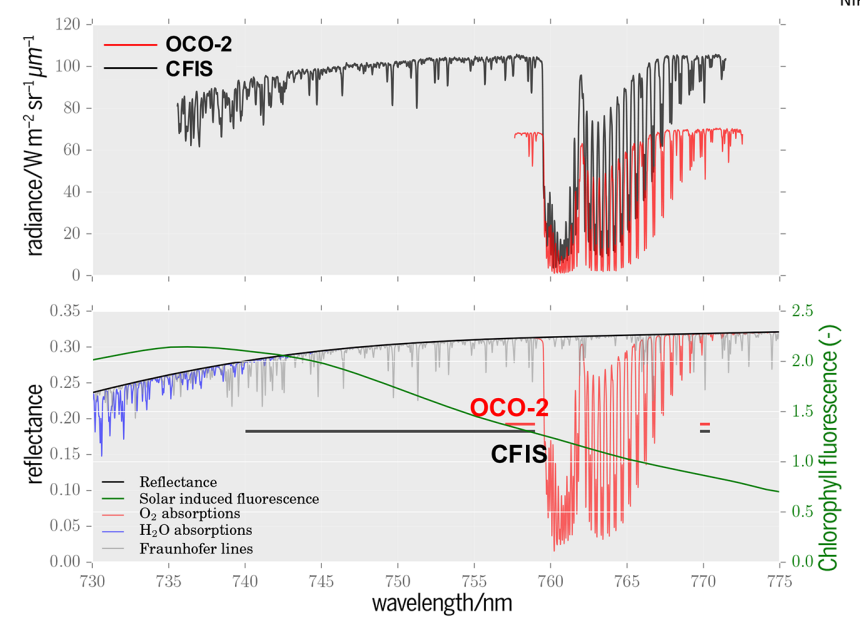

B
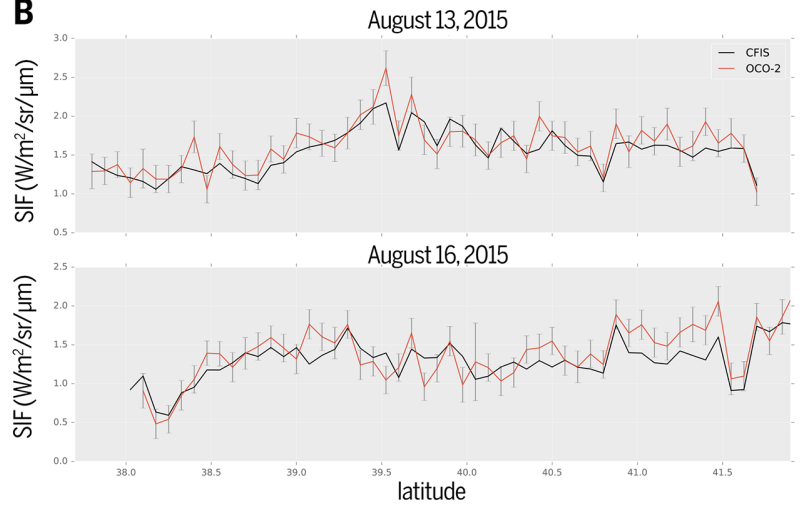

Fig. 2. Instrument characteristics and SIF retrievals with CFIS. (A) Spectral coverage and SIF retrieval windows for both OCO-2 (red) and CFIS (black). (B) Two initial validation flights for OCO-2 SIF on 13 and 16 August 2015. Error bars represent the SE of the OCO-2 SIF retrieval.

(C) Fine-scale CFIS SIF retrievals over agricultural areas in southwest Minnesota, together with the RGB imagery derived from a four-band (RGB + NIR) context camera and NDVI at a finer spatial resolution ( $<1 \mathrm{~m}$ as opposed to 10 to $20 \mathrm{~m}$ of CFIS). Note that different resolutions between CFIS and context camera images should not be confused with each other, as the longer exposure time of the former results in elongated pixels along the flight track. The region affected by partial cloud cover is highlighted by the red box. net ecosystem exchange measured with the EC technique (32) at these sites. We found that the SIF-GPP relationship is consistent across distinct vegetation types (Fig. 3A). This finding is different from previous reports that suggested highly variable biome-dependent relationships (13). There may be multiple explanations for the potential divergence in their SIF-GPP relationships. One possibility is the effect of the differences across biomes in plant physiology and canopy structure such as leaf angle orientation, leaf clumping, leaf area index, and chlorophyll profiles (8). Such effect has also been demonstrated through model simulations (33). Yet another possibility is the potential systematic bias in either SIF or GPP products. To investigate this latter possibility, we repeated our analyses using both FLUXCOM (34) and Moderate Resolution Imaging Spectroradiometer (MODIS) GPP products $(35,36)$ at flux towerspecific pixels during the OCO-2 overpass dates. FLUXCOM GPP is a data set derived from statistically upscaled EC measurements, whereas MODIS GPP is a data set modeled with the light-use efficiency concept. In these analyses, the obtained SIF-GPP relationships diverge among biomes (Fig. 3, B and C), especially for MODIS products. This indicates that the highly biome-dependent SIF-GPP relationships, as found in previous studies, may at least partly result from systematic biases in GPP data sets whose production inevitably involves assumptions and models, as GPP cannot be directly measured at regional or global scales (37).

Although it is tempting to think about a universal SIF-GPP relationship across biomes (Fig. 3A), the existence of biome-specific relationships cannot be ruled out at present. Just a few EC sites are located in the direct or close vicinity of OCO-2 orbits, and the OCO-2 lifetime is still short, limiting our analyses. Only continued research with more land biomes and growing data records can reveal the true discrepancies or consistencies underlying this relationship and the responsible mechanisms.

The following simple equations, however, show the possibility of variable SIF-GPP relationships among biomes but also point to plausible mechanisms if a universal relationship does exist. Traditionally, the simplest way to model GPP is through the approach of light-use efficiency of $\mathrm{CO}_{2}$ assimilation $\left(\Phi_{\mathrm{CO}_{2}}\right)$ (35) via the Monteith theory (38)

$$
G P P=\Phi_{\mathrm{CO}_{2}} \alpha I
$$

Here, $I$ is the photosynthetically active radiation (PAR) incident upon the canopy, and $\alpha$ is the canopy absorbance of PAR. This approach has been widely used, particularly in the field of vegetation remote sensing (36). To effectively use this method, measuring $I$ is not enough; one must also know both $\Phi_{\mathrm{CO}_{2}}$ and $\alpha$, which are extremely difficult to determine at large scales and can change with environmental conditions and vegetation types. However, the task becomes somewhat easier if SIF is known. For SIF, a similar relationship holds via the Berry equation (16)

$$
S I F=\Phi_{\mathrm{F}} \alpha I \beta
$$


A

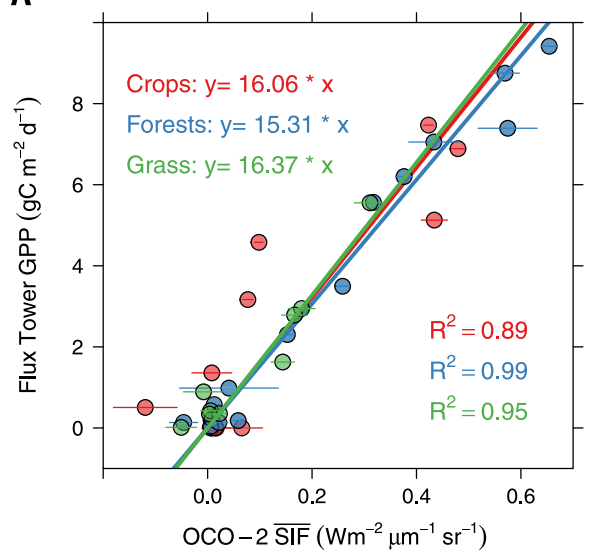

B

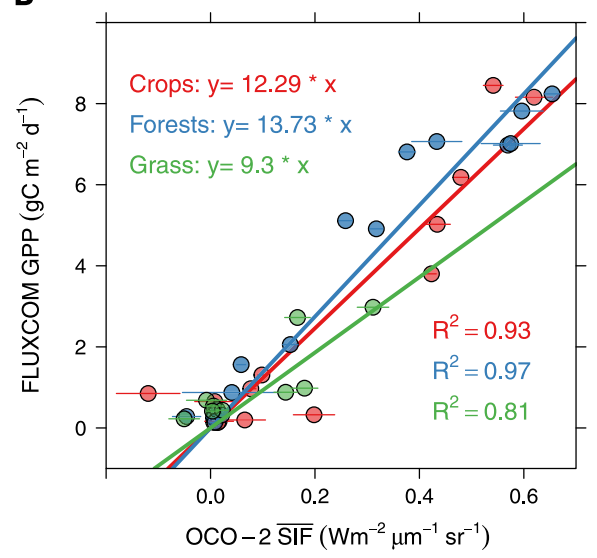

C

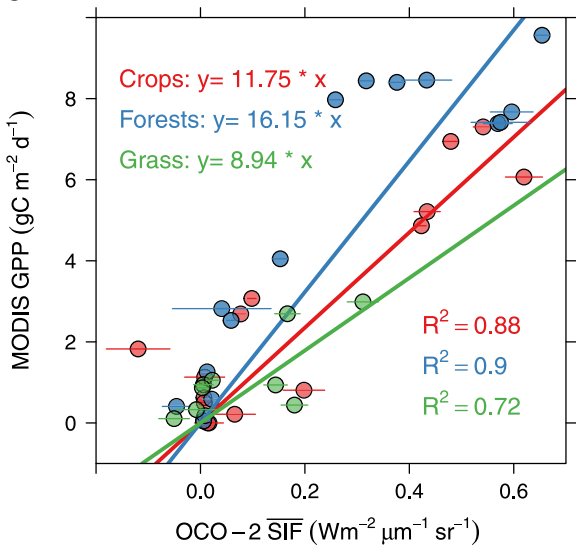

Fig. 3. SIF-GPP relationships. The relationship between GPP and OCO-2 SIF (daily mean value, denoted as SIF, converted from instantaneous measurements) at three flux tower sites representative of three different biomes: crops (Minnesota Tall Tower KCMP) (30), grass (Stuart Plain in Australia) (31), and deciduous temperate forests [Missouri Ozark site (US_MOz)]. The first two sites are selected because they are in the direct underpass of OCO-2 orbital tracks; for the US_MOz site, OCO-2 SIF retrievals are obtained from representative forests in the vicinity of the tower. The KCMP footprint covers a mixture of corn, soybean, and grasses but is dominated by the two major crops. Error bars represent the SE of the OCO-2 SIF retrieval. Daily GPP in the 2015 growing season is obtained during the OCO-2 overpasses from (A) eddy covariance measurements, (B) FLUXCOM products, and (C) MODIS products, sampled these three flux sites. Both FLUXCOM and MODIS GPP are 8-day products and are linearly interpolated to the OCO-2 overpass dates. The site-specific FLUXCOM GPP value is extracted from the grid cell $\left(0.083^{\circ}\right.$ by $\left.0.083^{\circ}\right)$ that corresponds to the latitude and longitude of the tower location. The sitespecific MODIS (MOD17A2) GPP value is the average of nine adjacent pixels $(1 \mathrm{~km}$ by $1 \mathrm{~km})$ centered at the tower location. Both are roughly equivalent to $\sim 9-\mathrm{km}^{2}$ area.
Here, $\Phi_{\mathrm{F}}$ is the light-use efficiency of SIF, and $\beta$ is the probability of SIF photons escaping the canopy. Combining Eqs. 1 and 2 leads to

$$
G P P=\frac{\Phi_{\mathrm{CO}_{2}}}{\beta \Phi_{\mathrm{F}}} S I F
$$

which relates SIF to GPP.

Equations 1 to 3 may not be the most mechanistic way to describe the relationship between SIF and GPP and its potential variations with a multitude of biotic and abiotic factors across different climates and biomes. A more mechanistic alternative involves the description of processes such as energy partitioning between photosystem I and II, canopy structure, stoichiometry and fluorescing properties of these two photosystems, photorespiration, photosynthetic pathways (C3 versus C4), linear and cyclic electron transports, and fluorescence radiative transfer modeling in canopies (8). Although such a complex approach will be important for developing the knowledge base needed to bridge the gap between bottomup biophysical modeling and empirical top-down constraints, Eqs. 1 to 3 offer a convenient framework for presenting and evaluating arguments and counterarguments for the SIF-GPP relationship.

An important difference between Eqs. 3 and 1 is that the former involves a ratio of two potentially covarying terms of energy-use efficiency, whereas the latter uses the product of two independent variables. The variability of $\beta$ likely depends on canopy geometry, solar elevation, view angle, and other conditions. $\Phi_{\mathrm{CO}_{2}}$ and $\Phi_{\mathrm{F}}$ are also not constants at the leaf scale (9). $\Phi_{\mathrm{CO}_{2}}$ varies with photosynthetic capacities and environmental conditions (such as light, atmospheric $\mathrm{CO}_{2}$, and humidity) in a way that is typically predicted with the Farquhar-von Caemmerer-Berry model of photosynthesis (39). $\Phi_{\mathrm{F}}$ changes with environmental conditions that affect photochemical and nonphotochemical quenching (8). Thus, it seems natural to assume that the slope of the GPP-SIF relationship will vary across biomes. A universal SIF-GPP linear relationship would at least require interbiome variations in $\Phi_{\mathrm{CO}_{2}}$ and $\Phi_{\mathrm{F}}$ to cancel each other, a scenario that seems difficult to realize. Clearly, more in-depth processbased studies are needed to understand the nature of the SIF-GPP relationship. A particular emphasis should be placed on the covariation between $\Phi_{\mathrm{CO}_{2}}$ and $\Phi_{\mathrm{F}}$ at different spatiotemporal scales, which will be key to using SIF as a shortcut to estimating GPP at large scales (40).

\section{Consistent spatiotemporal variations in SIF and GPP revealed by OCO-2}

So far we have focused on the characteristics of OCO-2 SIF and its relationship with GPP at fine scales. We now address the question of to what extent SIF can be used to predict the spatiotemporal dynamics of GPP. To fully address this issue, both SIF and GPP products will have to be improved considerably. Nevertheless, this does not prevent us from using data already available to gain initial insights. We therefore employed the empirical orthogonal function (EOF) method to decompose the complex spatial and temporal variability of SIF and GPP into various orthogonal components. This analysis allows us to identify common patterns and discrepancies across noisy data sets that are usually characterized by nonlinearity and high dimensionality. We performed an EOF analysis on monthly data sets of OCO-2 SIF as well as FLUXCOM and MODIS GPP products and investigated their temporal and spatial coherences for each orthogonal component. Figure 4A shows the four leading EOF modes for all variables, ordered by how much variance in the data set each mode explains (fig. $\mathrm{S} 2$ ). For the first leading mode, all three variables closely match each other, except in tropical South America, explaining 63,74 , and $66 \%$ of the total variance in OCO-2 SIF, FLUXCOM GPP, and MODIS GPP, respectively. The corresponding time series depicts the seasonal dynamics, with all variables in good agreement with each other (Fig. 4B). The Pearson correlation coefficients between OCO-2 SIF and FLUXCOM GPP, quantifying their spatial similarity, are consistently high across all biomes in this first mode (Fig. 4C). Compared with the FLUXCOM product, MODIS GPP tends to have a lower correlation with OCO-2 SIF, especially in the tropical evergreen broadleaf forests. From the second mode onward, interesting discrepancies emerge between MODIS GPP and the other two data sets in different regions of the world. In South America, for example, the second mode of OCO-2 SIF and FLUXCOM GPP identifies a northeast-to-southwest stretch (the green positive phase), which is absent in MODIS GPP data. Similar contrast exists in the northern edge of tropical Africa. In the third and fourth modes, MODIS GPP shows a profound dipole in the central Amazon, which is not present in the other two data sets. These discrepancies have led to a lower correlation between OCO-2 SIF and MODIS GPP than with the FLUXCOM product (Fig. 4C), especially for the grassland and savanna systems. The time series of the second to fourth components also display a closer similarity between OCO-2 SIF and FLUXCOM GPP than with MODIS 
A
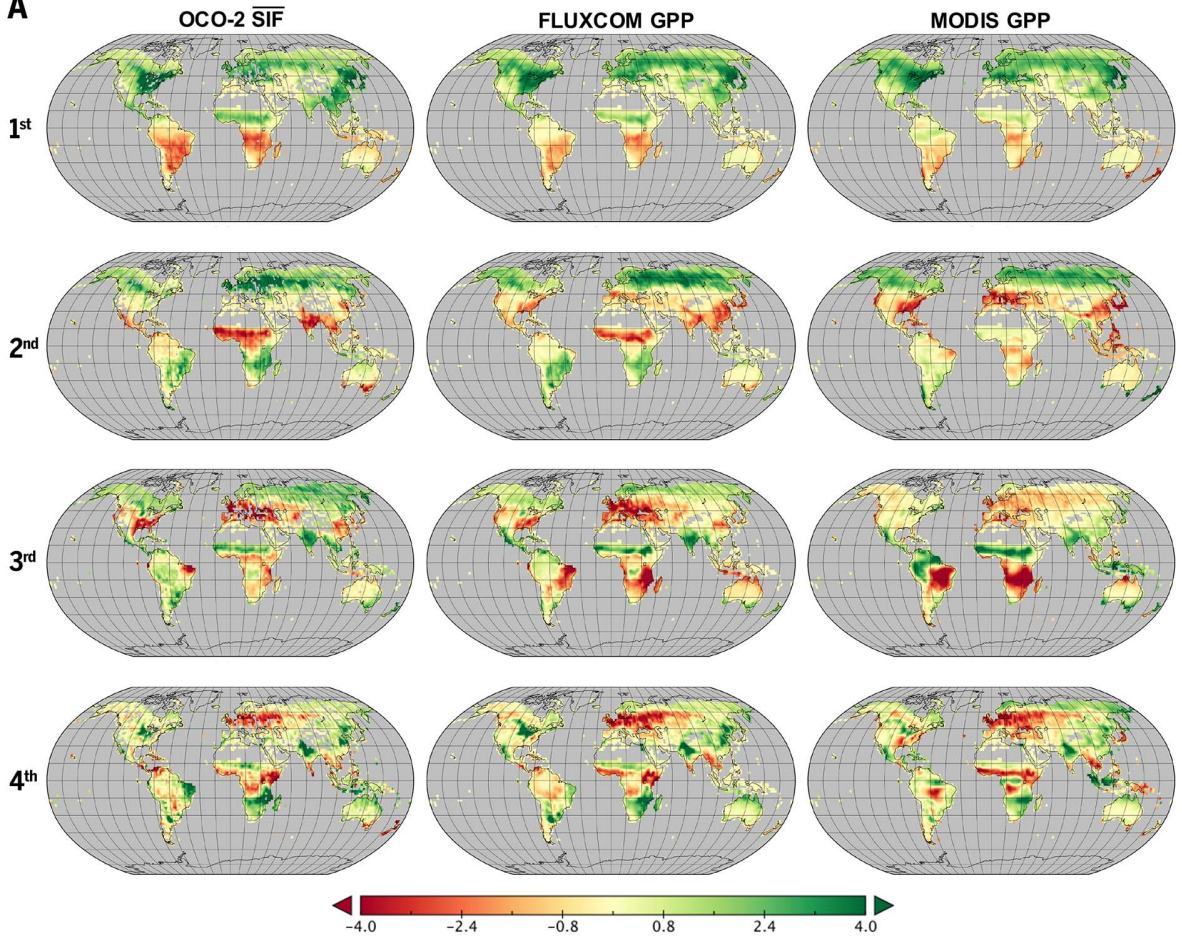

Fig. 4. Spatiotemporal patterns of EOF decomposition of OCO-2 SIF, FLUXCOM GPP, and MODIS GPP for the first four leading modes in descending order. (A) Spatial maps of EOFs from monthly data sets. (B) Corresponding time series of each EOF. (C) Quantification of the spatial resemblance of OCO-2 SIF with FLUXCOM (green) and MODIS GPP (white) across biomes, denoted as NF (needleleaf forests), scheme, following (11).
B

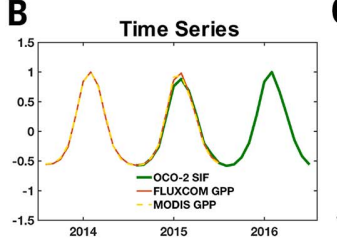

C Correlation Coefficients
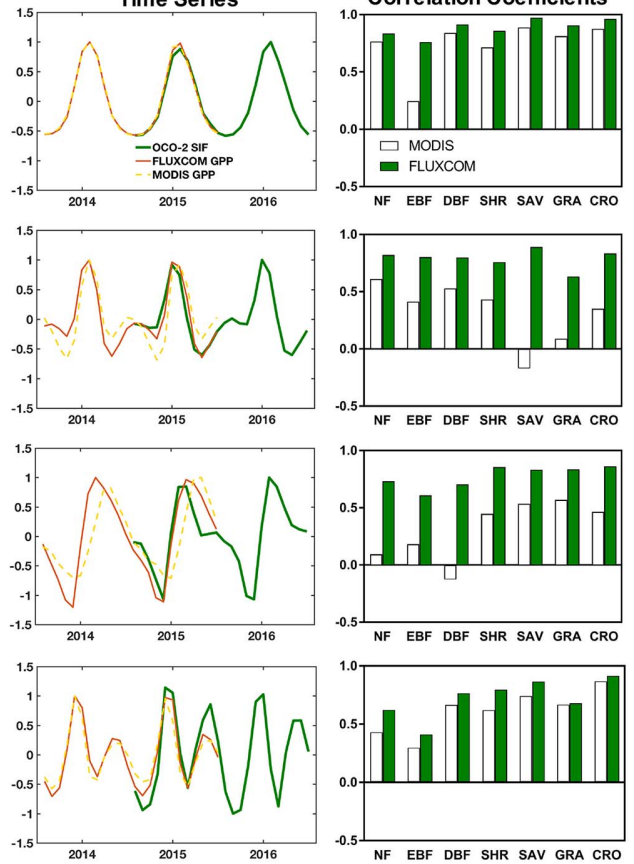

EBF (evergreen broadleaf forests), DBF (deciduous broadleaf forests), SHR (shrublands), SAV (savannas), GRA (grasslands), and CRO (croplands). The land cover data are from the International Satellite Land Surface Climatology Project Initiative II biome classification products using the International Geosphere-Biosphere Programme (IGBP)

GPP (Fig. 4B). The highly consistent correspondences, both in space and time, in the leading EOF modes of OCO-2 SIF and FLUXCOM GPP provide robust proof that SIF and GPP are governed by similar dynamics and controlled by similar environmental and biological conditions. In addition, these findings emphasize that SIF provides additional information compared with greenness-based productivity estimates, as the spatiotemporal variations are markedly different from the MODIS GPP product.

\section{Synergistic uses of OCO-2 SIF with other remote sensing products}

Past satellite observations (e.g., NDVI) have been largely based on surface spectral reflectance, which contains a mixture of information about green vegetation elements (e.g., contents of different pigments, leaf amount, and spatial arrangement), nongreen biomass elements, and underlying soil (41). They represent the best structural descriptions of the land surface at large scales and can be used synergistically with the SIF functional quantification of vegetation to understand and predict terrestrial ecosystem dynamics under changing environmental conditions. For example, phenology, which is a key driver of terrestrial carbon uptake (42), is routinely monitored by conventional reflectance-based remote sensing (e.g., MODIS). Therefore, remotely sensed phenol- ogy data sets can be combined with OCO-2 SIF products to study how vegetation phenology affects the SIF dynamics, which will help to illuminate the causes for the potential biome-dependent SIF-GPP relationships at different phenological stages. Conventional vegetation indices and SIF products could also be used to compare efficiencies of different farming practices around the world and to monitor drought stress (18). In these aspects, the OCO-2 SIF data sets will be particularly valuable for synergistic use with conventional vegetation indices obtained globally at spatial resolutions of $30 \mathrm{~m}$ and finer (e.g., Landsat and Sentinel-2).

Another potential application is to integrate OCO-2 SIF with $\mathrm{CO}_{2}$ concentration measurements to disentangle the net fluxes derived from atmospheric $\mathrm{CO}_{2}$ data into process-specific and, thus, information-rich gross fluxes-namely GPP, ecosystem respiration, and anthropogenic components. Additionally, SIF could also be used as a prior constraint on GPP for atmospheric transport inversion models or in data assimilation frameworks for such purposes (43).

With growing data records, OCO-2 SIF will provide a robust benchmark for upcoming missions such as OCO-3, FLEX, the TROPOspheric Monitoring Instrument (TROPOMI) (26), and the Geostationary Carbon Cycle Observatory (GeoCARB) (44). In addition, tracking the sub- daily variation of SIF will be possible by combining OCO-2 products with products from these upcoming satellite missions. These endeavors will lead to valuable data sets that can be used in a variety of ecological research, prediction, and management activities. Despite the lack of contiguous global coverage, OCO-2's measurements can be considered a cornerstone toward more optimal SIF data sets that can fulfill even greater requirements in terms of accuracy, spatial coverage, and resolution and can thus unleash the power of SIF in revealing global photosynthetic activities.

\section{Summary}

OCO-2 provides a high-resolution SIF data set that allows direct validation against groundbased and airborne SIF observations. With this data set, it is possible to resolve diverse heterogeneous landscape patterns in SIF emission. These capabilities have been challenging for previous satellite missions that produced SIF retrievals. The EOF analyses of the validated OCO-2 SIF data set and GPP products revealed that the spatiotemporal variations of SIF and GPP are highly consistent, suggesting that SIF is a powerful proxy for GPP. We also found that the relationship between SIF and GPP, when the latter is directly obtained at eddy flux sites in the vicinity of OCO-2 orbits, is more consistent across biomes than 
was suggested by earlier studies. However, future investigations with expanded data sets will need to test the robustness of this finding across all land biomes. Despite this uncertainty, it is clear that high-quality satellite SIF is of central importance to studying terrestrial ecosystem dynamics and carbon cycle. Eventual synergistic uses of SIF with atmospheric $\mathrm{CO}_{2}$ enabled by OCO-2 will lead to more reliable estimates of terrestrial carbon sources and sinks and a deeper understanding of carbon-climate feedbacks.

\section{REFERENCES AND NOTES}

1. R. J. Norby et al., Forest response to elevated $\mathrm{CO}_{2}$ is conserved across a broad range of productivity. Proc. Natl. Acad. Sci. U.S.A. 102, 18052-18056 (2005). doi: 10.1073/ pnas.0509478102; pmid: 16330779

2. P. Friedlingstein et al., Climate-carbon cycle feedback analysis: Results from the C4MIP model intercomparison. J. Clim. 19, 3337-3353 (2006). doi: 10.1175/JCLI3800.1

3. C. Huntingford et al., Simulated resilience of tropical rainforests to $\mathrm{CO}_{2}$-induced climate change. Nat. Geosci. 6 , 268-273 (2013). doi: 10.1038/ngeo1741

4. C. Rosenzweig et al., Assessing agricultural risks of climate change in the 21st century in a global gridded crop model intercomparison. Proc. Natl. Acad. Sci. U.S.A. 111, 3268-3273 (2014). doi: 10.1073/pnas.1222463110; pmid: 24344314

5. D. Schimel et al., Observing terrestrial ecosystems and the carbon cycle from space. Glob. Change Biol. 21. 1762-1776 (2015). doi: 10.1111/gcb.12822; pmid: 25472464

6. G. C. Papageorgiou, Govindjee, in Non-Photochemical Quenching and Energy Dissipation in Plants, Algae and Cyanobacteria, B. Demmig-Adams, G. Garab, W. Adams III, Govindjee, Eds. (Springer, 2014), pp. 1-44.

7. N. R. Baker, Chlorophyll fluorescence: A probe of photosynthesis in vivo. Annu. Rev. Plant Biol. 59, 89-113 (2008). doi: 10.1146/annurev.arplant.59.032607.092759; pmid: 18444897

8. A. Porcar-Castell et al., Linking chlorophyll a fluorescence to photosynthesis for remote sensing applications: Mechanisms and challenges. J. Exp. Bot. 65, 4065-4095 (2014) doi: 10.1093/jxb/eru191; pmid: 24868038

9. B. Genty, J.-M. Briantais, N. R. Baker, The relationship between the quantum yield of photosynthetic electron transport and quenching of chlorophyll fluorescence. Biochim. Biophys. Acta, Gen. Subj. 990, 87-92 (1989). doi: 10.1016/S0304 4165(89)80016-9

10. G. H. Krause, E. Weis, Chlorophyll fluorescence and photosynthesis: The basics. Annu. Rev. Plant Physiol. Plant Mol. Biol. 42, 313-349 (1991). doi: 10.1146/annurev. pp.42.060191.001525

11. C. Frankenberg et al., New global observations of the terrestrial carbon cycle from GOSAT: Patterns of plant fluorescence with gross primary productivity. Geophys. Res. Lett. 38, L17706 (2011). doi: 10.1029/2011GL048738

12. J. Joiner et al., First observations of global and seasonal terrestrial chlorophyll fluorescence from space. Biogeosciences 8, 637-651 (2011). doi: 10.5194/bg-8-637-2011

13. L. Guanter et al., Retrieval and global assessment of terrestrial chlorophyll fluorescence from GOSAT space measurements. Remote Sens. Environ. 121, 236-251 (2012). doi: 10.1016/ j.rse.2012.02.006

14. J. Joiner et al., Global monitoring of terrestrial chlorophyll fluorescence from moderate-spectral-resolution near-infrared satellite measurements: Methodology, simulations, and application to GOME-2. Atmos. Meas. Tech. 6, 2803-2823 (2013). doi: 10.5194/amt-6-2803-2013

15. P. Köhler, L. Guanter, J. Joiner, A linear method for the retrieval of sun-induced chlorophyll fluorescence from GOME-2 and
SCIAMACHY data. Atmos. Meas. Tech. 8, 2589-2608 (2015). doi: 10.5194/amt-8-2589-2015

16. J.-E. Lee et al., Forest productivity and water stress in Amazonia: Observations from GOSAT chlorophyll fluorescence. Proc. Biol. Sci. 280, 20130171 (2013). doi: 10.1098/ rspb.2013.0171; pmid: 23760636

17. N. C. Parazoo et al., Interpreting seasonal changes in the carbon balance of southern Amazonia using measurements of $\mathrm{XCO}_{2}$ and chlorophyll fluorescence from GOSAT. Geophys. Res. Lett. 40, 2829-2833 (2013). doi: 10.1002/grl.50452

18. Y. Sun et al., Drought onset mechanisms revealed by satellite solar-induced chlorophyll fluorescence: Insights from two contrasting extreme events. J. Geophys. Res. Biogeosci. 120 2427-2440 (2015). doi: 10.1002/2015JG003150

19. Y. Yoshida et al., The 2010 Russian drought impact on satellite measurements of solar-induced chlorophyll fluorescence: Insights from modeling and comparisons with parameters derived from satellite reflectances. Remote Sens. Environ. 166, 163-177 (2015). doi: 10.1016/j.rse.2015.06.008

20. K. Guan et al., Improving the monitoring of crop productivity using spaceborne solar-induced fluorescence. Glob. Change Biol. 22, 716-726 (2016). doi: 10.1111/gcb.13136; pmid: 26490834

21. J. Joiner et al., The seasonal cycle of satellite chlorophyll fluorescence observations and its relationship to vegetation phenology and ecosystem atmosphere carbon exchange. Remote Sens. Environ. 152, 375-391 (2014). doi: 10.1016/ j.rse.2014.06.022

22. S. Walther et al., Satellite chlorophyll fluorescence measurements reveal large-scale decoupling of photosynthesis and greenness dynamics in boreal evergreen forests. Glob. Change Biol. 22, 2979-2996 (2016). doi: 10.1111/gcb.13200 pmid: 26683113

23. L. Guanter et al., Global and time-resolved monitoring of crop photosynthesis with chlorophyll fluorescence. Proc. Natl. Acad. Sci. U.S.A. 111, E1327-E1333 (2014). doi: 10.1073/ pnas.1320008111; pmid: 24706867

24. C. Frankenberg et al., Prospects for chlorophyll fluorescence remote sensing from the Orbiting Carbon Observatory-2. Remote Sens. Environ. 147, 1-12 (2014). doi: 10.1016/ j.rse.2014.02.007

25. M. Rossini et al., Analysis of red and far-red sun-induced chlorophyll fluorescence and their ratio in different canopies based on observed and modeled data. Remote Sens. 8, 412 (2016). doi: 10.3390/rs8050412

26. L. Guanter et al., Potential of the TROPOspheric Monitoring Instrument (TROPOMI) onboard the Sentinel-5 Precursor for the monitoring of terrestrial chlorophyll fluorescence. Atmos. Meas. Tech. 8, 1337-1352 (2015). doi: 10.5194/amt-8-1337-2015

27. M. Drusch et al., The FLuorescence EXplorer Mission ConceptESA's Earth Explorer 8. IEEE Trans. Geosci. Remote Sens. 55, 1273-1284 (2017). doi: 10.1109/TGRS.2016.2621820

28. U. Rascher et al., Sun-induced fluorescence - a new probe of photosynthesis: First maps from the imaging spectrometer HyPlant. Glob. Change Biol. 21, 4673-4684 (2015). doi: 10.1111/gcb.13017; pmid: 26146813

29. S. Wieneke et al., Airborne based spectroscopy of red and far-red sun-induced chlorophyll fluorescence: Implications for improved estimates of gross primary productivity. Remote Sens. Environ. 184, 654-667 (2016). doi: 10.1016/j.rse.2016.07.025

30. J. D. Wood et al., Multiscale analyses of solar-induced florescence and gross primary production. Geophys. Res. Lett. 44, 533-541 (2017). doi: 10.1002/2016GL070775

31. M. Verma et al., Effect of environmental conditions on the relationship between solar-induced fluorescence and gross primary productivity at an OzFlux grassland site. J. Geophys. Res. Biogeosci. 122, 716-733 (2017). doi: 10.1002/2016JG003580

32. D. Baldocchi et al., FLUXNET: A new tool to study the temporal and spatial variability of ecosystem-scale carbon dioxide, water vapor, and energy flux densities. Bull. Am. Meteorol. Soc. 82, 2415-2434 (2001). doi: 10.1175/1520 0477(2001)082<2415:FANTTS>2.3.C0;2
33. J. Verrelst et al., Evaluating the predictive power of sun-induced chlorophyll fluorescence to estimate net photosynthesis of vegetation canopies: A SCOPE modeling study. Remote Sens. Environ. 176, 139-151 (2016). doi: 10.1016/j.rse.2016.01.018

34. G. Tramontana, M. Jung, G. Camps-valls, K. Ichii, B. Raduly, Predicting carbon dioxide and energy fluxes across global FLUXNET sites with regression algorithms. Biogeosciences 13 , 4291-4313 (2016). doi: 10.5194/bg-13-4291-2016

35. S. W. Running et al., A continuous satellite-derived measure of global terrestrial primary production. Bioscience 54 , 547-560 (2004). doi: 10.1641/0006-3568(2004)054[0547: ACSMOG]2.0.CO;2

36. M. Zhao, S. W. Running, Drought-induced reduction in global terrestrial net primary production from 2000 through 2009. Science 329, 940-943 (2010). doi: 10.1126/ science.1192666; pmid: 20724633

37. A. Anav et al., Spatiotemporal patterns of terrestrial gross primary production: A review. Rev. Geophys. 53, 785-818 (2015). doi: 10.1002/2015RG000483

38. J. L. Monteith, Solar radiation and productivity in tropical ecosystems. Source J. Appl. Ecol. 9, 747-766 (1972). doi: 10.2307/2401901

39. G. D. Farquhar, S. von Caemmerer, J. A. Berry, A biochemical model of photosynthetic $\mathrm{CO}_{2}$ assimilation in leaves of $\mathrm{C}_{3}$ species. Planta 149, 78-90 (1980). doi: 10.1007/BF00386231; pmid: 24306196

40. T. S. Magney et al., Connecting active to passive fluorescence with photosynthesis: A method for evaluating remote sensing measurements of Chl fluorescence. New Phytol. 215, 1594-1608 (2017). doi: 10.1111/nph.14662; pmid: 28664542

41. A. Huete et al., Overview of the radiometric and biophysical performance of the MODIS vegetation indices. Remote Sens. Environ. 83, 195-213 (2002). doi: 10.1016/S00344257(02)00096-2

42. T. Keenan et al., Net carbon uptake has increased through warming-induced changes in temperate forest phenology. Nat. Clim. Chang. 4, 598-604 (2014). doi: 10.1038/nclimate2253

43. N. C. Parazoo et al., Terrestrial gross primary production inferred from satellite fluorescence and vegetation models. Glob. Change Biol. 20, 3103-3121 (2014) doi: 10.1111/gcb.12652; pmid: 24909755

44. I. N. Polonsky, D. M. O'Brien, J. B. Kumer, C. W. O'Dell the geoCARB Team, Performance of a geostationary mission, geoCARB, to measure $\mathrm{CO}_{2}, \mathrm{CH}_{4}$ and $\mathrm{CO}$ column-averaged concentrations. Atmos. Meas. Tech. 7, 959-981 (2014) doi: 10.5194/amt-7-959-2014

45. C. G. Homer et al., Completion of the 2011 National Land Cover Database for the conterminous United States-Representing a decade of land cover change information. Photogramm. Eng. Remote Sens. 81, 345-354 (2015).

\section{ACKNOWLEDGMENTS}

A portion of this research was carried out at the Jet Propulsion Laboratory, California Institute of Technology, under a contract with NASA. A.P.-C. is funded by the Academy of Finland (Research Fellow grant 1288039). L. Gu and J.D.W. are supported by the U.S. Department of Energy Biological and Environmental Research program through Oak Ridge National Laboratory's Terrestrial Ecosystem Science (TES) Science Focus Area (SFA). M.J. acknowledges support from the European Union H2O2O Biosphere Atmosphere Change Index project (grant 640176). We thank the data providers of FLUXCOM and MODIS for their contribution. The OCO-2 SIF data set is publicly available at https://co2.jpl.nasa.gov. The CFIS SIF retrieval and GPP inferred at flux towers are available upon request.

\section{SUPPLEMENTARY MATERIALS}

www.sciencemag.org/content/358/6360/eaam5747/suppl/DC1 Figs. S1 and S2

11 December 2016; accepted 7 July 2017

10.1126/science.aam5747 